\title{
Reconstruction of road accident using video recording
}

\author{
Stawomir Tarkowski ${ }^{1, *}$, Aleksander Nieoczym², ${ }^{2}$ acek Caban $^{3}$, Leszek Gardyński ${ }^{4}$ and Jan Vrabel $^{5}$ \\ ${ }^{1}$ Lublin University of Technology, Faculty of Mechanical Engineering, Department of Automotive Vehicles, Nadbystrzycka 36, \\ 20-618 Lublin, Poland \\ ${ }^{2}$ Lublin University of Technology, Faculty of Mechanical Engineering, Department of Machine Design and Mechatronics, \\ Nadbystrzycka 36, 20-618 Lublin, Poland \\ ${ }^{3}$ University of Life Sciences in Lublin, Faculty of Production Engineering, Department of Agricultural, Forestry and Transport \\ Machines, Głęboka 28, 20-612 Lublin, Poland \\ ${ }^{4}$ Lublin University of Technology, Faculty of Mechanical Engineering, Department of Materials Engineering, Nadbystrzycka 36, \\ 20-618 Lublin, Poland \\ ${ }^{5}$ University of Zilina, Faculty of Operation and Economics of Transport and Communications, Department of Road and Urban \\ Transport, Univerzitná 8215/1, 010-26 Žilina, Slovakia
}

\begin{abstract}
Presented was the procedure of reconstructing a motorcycle-motor car collision with both vehicles moving in the same direction and performing simultaneous manoeuvres: a left turn and overtaking. Because of the conflicting reports of witnesses, the procedure also involved recordings from a stationary video camera. These data allowed us to retrace the movement and manoeuvres of vehicles as a function of time and then to identity the perpetrator of the accident.
\end{abstract}

\section{Introduction}

Road safety depends on many factors, including the efficiency of the technical system and the behaviour of the driver of the vehicle. The systematic increase in the number of vehicles in road traffic is the cause of the risks associated with their use [1]. Except undoubted advantages, it causes a great growth of traffic volume of road network and a constantly increasing demand on traffic and its safety [2]. The negative effect caused by traffic congestion is most notable in the largest cities, where traffic density is relatively high, with characteristically low and often variable speed (acceleration and deceleration) [3]. Therefore, the traffic accident rate is an important criterion in planning, building, renovation, and maintenance of road network [2]. In the literature we can find publications $[4,5]$ about the issue of construction of traffic infrastructure and equipment as well as a particular traffic operation when providing a transport and logistics services, which have an impact on transport safety. Cernicky et al., in works [6, 7] suggest that one of the possibilities of traffic accidents number reduction is implementation of ITS on the chosen part of communication network. Skrúcaný et al., $[8,9]$ investigated dangers related to heavy goods vehicle transportation under different loads and in varying conditions of operating as well as during braking process.

Various types of vehicles take part in road traffic, from two-wheelers to passenger cars, vans, public transport vehicles, light trucks and others. Traffic statistics confirm that despite the fact that motorcyclists account for a few percent of all road users, they are involved in a disproportionately high number of collisions. This phenomenon has already been the subject of multi-faceted research and analyses $[10,11,12]$. They determined the relationship between the age of motorcyclists, engine capacity, type of motorcycle and the probability of a collision. Motorcyclists are associated with aggressive style of driving, speeding, overtaking in prohibited places, or overtaking and passing other road users on their right and left $[13,14]$.

Analysis of the causes of accidents also points to another reason. A motorcycle-motor vehicle collision is often a result of the fact that the driver has not noticed the motorcyclist, which is also known as the "looked-butfailed-to-see" phenomenon $[10,15,16]$. When deciding to perform the manoeuvre, the driver of the vehicle does not see the danger in the mirror. At the given time, the driver does not observe in his field of view the rapidly approaching motorcycle. This is the case also in situations where a road user fails to give way to a motorcyclist coming from the opposite direction. This happens even if the road user is looking in the direction of the approaching motorcycle; however, his sensory perception does not treat the image of the motorcycle as a threat. This behaviour is often due to a very common incorrect assessment of the speed of the motorcycle and its distance from the vehicle [10], on account of their small frontal area [16].

Investigation of the causes of accidents is always hampered by cases of varying interpretation and discrepancies between the testimonies of persons directly involved in the collision and sometimes even witnesses $[10,17]$.

\footnotetext{
*Corresponding author: s.tarkowski@pollub.pl
} 


\section{Description of the analysed problem}

The accident was the result of the collision of the motorcycle, whose rider was overtaking a column of vehicles, with the passenger car, whose driver started a left turn manoeuvre.

In this case, the main task was to determine whether the driver of the car did or did not signal the left turn before performing the manoeuvre. It was also necessary to determine whether during overtaking the motorcyclist was moving faster than it was allowed and whether he could react to the car driver's manoeuvre. The video recording showed a column of vehicles moving in the following order: an unidentified dark coloured car (car X), a white Opel Astra involved in the accident (car 1), a dark coloured Opel Corsa (car 2) and a Kawasaki motorcycle, which was also involved in the accident (motorcycle 3 ). The collision occurred when the left front corner of the car 1 was at the broken line delineating the edge of the roadway, between the second and third painted lines. At the time of the collision, the car 1 had not yet crossed this line. It was difficult to read from the recording where exactly the motorcyclist crossed the axis of the road when overtaking, or whether the driver of the car 1 signalled the left turn prior to the manoeuvre.

The course of the collision was presented in diverse ways by its participants. The driver of car 1 reported that before turning left slowed down and turned on the left turn signal. Prior to turning left, he again looked in the mirror, but none of the vehicles following him was signalling the overtaking manoeuvre and he did not see the motorcycle, either. He performed the turning manoeuvre smoothly and without stopping. The rider of motorcycle 3 testified that he moved in a column behind other cars at a speed of about $50 \mathrm{~km} / \mathrm{h}$. In front of him, he saw two cars with a distance of approx. 15-20 m between them. After making sure that the opposite lane was free, he turned on the left turn signal while the line on the road was still solid and then started overtaking. He crossed the axis of the road when it was marked with the broken line. After moving onto the opposite lane and driving about 5 meters he noticed the car 1; it was not signalling a left turn, and its driver pulled to the axis of the road. When the motorcycle reached the level of the car 1, its driver turned to the left and blocked the motorcycle's path. The motorcyclist was unable to perform any defensive manoeuvres and the collision occurred.

\section{Reconstruction of the course of the collision on the basis of the video recording}

While moving relative to the camera, the vehicles seen in the recording were passing reference points visible in the frame (trees and a road location marker). They were designated with numbers I - VI - Fig. 1. After the identification of these points, it was necessary to determine the distance between them. Other measurements concerned the distribution of landmarks in the form of road marking elements. The following distances from the right edge of the road were measured: the position of the beginning and end of the double solid line after the intersection and the solid left edge line.
Measurements at the scene of the accident included the distances between selected points of two different vehicle movement tracks, covered by the camera range:

- Centre of the right-hand lane - in the case of vehicle 1 , 2 and 3.

- Centre of the left-hand lane - in the case of motorcycle -3 .

Particular vehicles: To the vehicles 1, 2, 3 were given the following symbols for the individual moments in the time:

A - the appearance of motorcycle 3 in the field of view of the video camera after passing point I (time 18:51:54.8 s);

B - the appearance of car 1 in the field of view of the camera after passing point IV (time 18:51:55.8 s);

$\mathbf{C}$ - the appearance of car 1 after passing point $\mathrm{V}$ and the car 2 after passing point III in the field of view of the camera (time 18:51:57.0 s);

D - beginning of the left turn and crossing of the axis of the road by the car 1 (time 18:51:58.2 s);

$\mathbf{U}$ - collision of the vehicles (time 18:51:59.0).

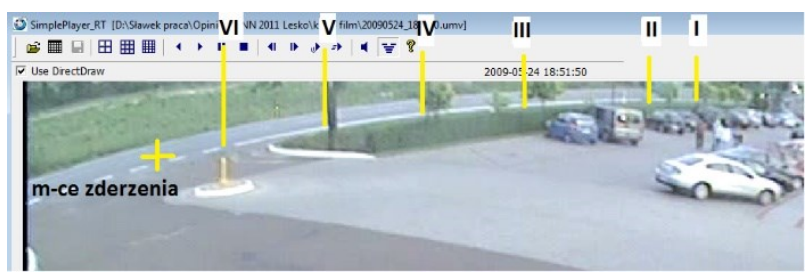

Fig. 1. Distribution of selected reference point.

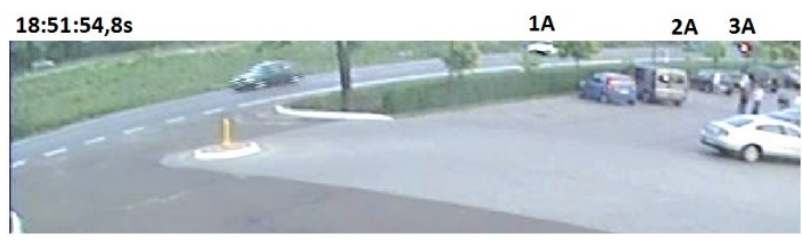

Fig. 2. A shot from the camera recording showing the start of the temporal and spatial analysis and the moment motorcycle 3 begins to accelerate.

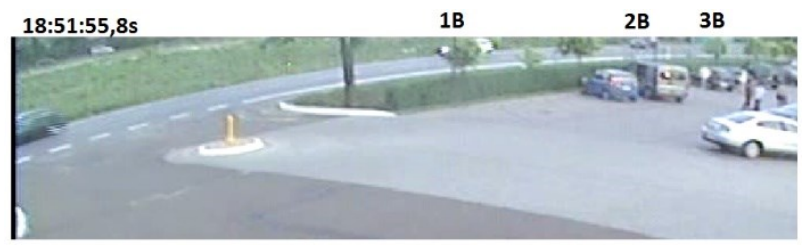

Fig. 3. A shot from the camera recording showing the moment when the car 1 begins to decelerate. 


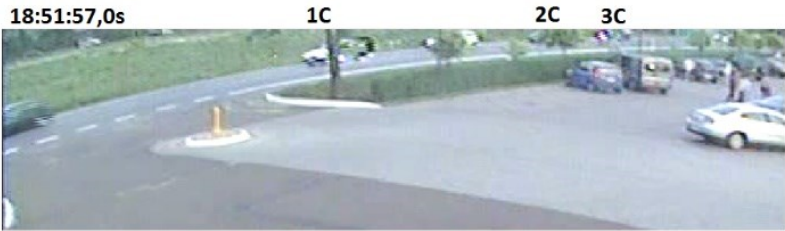

Fig. 4. A shot from the camera recording showing the moment when the motorcycle reaches the level of the car 2 .



Fig. 5. A shot from the camera recording showing the moment the car 2 passes point III in the field of view of the camera.

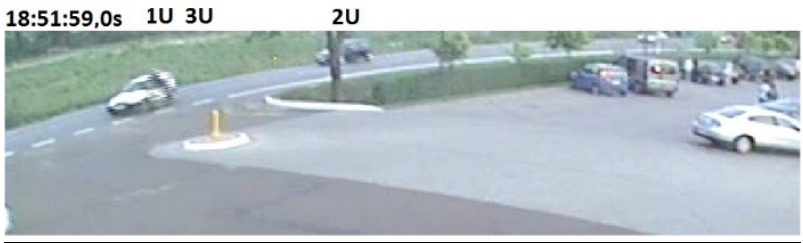

Fig. 6. A shot from the camera recording showing the collision of the motorcycle with the car 1 .

The recording frequency of the monitoring system was $5 \mathrm{~Hz}$, so each frame of the video recording presented the positions of vehicles in increments of $0.2 \mathrm{~s}$. Based on the data, the duration of the passage of vehicles between the selected reference points was determined. Knowing the length of the section of the road visible in the frame, it was possible to calculate the average speed of individual vehicles on the analysed section - Table 1 .

Table 1. Results of the analysis of the video recording

\begin{tabular}{|c|c|c|c|c|c|c|c|c|c|c|}
\hline \multirow[b]{2}{*}{$\begin{array}{l}\text { The } \\
\text { length of } \\
\text { the } \\
\text { section of } \\
\text { the road }\end{array}$} & \multirow[b]{2}{*}{$\begin{array}{l}\text { Length } \\
\text { of the } \\
\text { section } \\
\text { to the } \\
\text { right lane } \\
{[\mathrm{m}]}\end{array}$} & \multirow[b]{2}{*}{$\begin{array}{c}\text { Length of } \\
\text { the section } \\
\text { to the left } \\
\text { lane of the } \\
\text { motorcycle } \\
{[\mathrm{m}]}\end{array}$} & \multicolumn{2}{|l|}{ Car X } & \multicolumn{2}{|l|}{ Car 1} & \multicolumn{2}{|l|}{ Car 2} & \multicolumn{2}{|c|}{ Motorcycle 3} \\
\hline & & & $\begin{array}{c}\text { Driving } \\
\text { time } \\
{[\mathrm{s}]}\end{array}$ & $\begin{array}{c}\text { Average } \\
\text { speed } \\
{[\mathrm{km} / \mathrm{h}]}\end{array}$ & $\begin{array}{c}\text { Driving } \\
\text { time } \\
{[\mathrm{s}]}\end{array}$ & $\begin{array}{c}\text { Average } \\
\text { speed } \\
{[\mathrm{km} / \mathrm{h}]}\end{array}$ & $\begin{array}{c}\text { Driving } \\
\text { time } \\
{[\mathrm{s}]}\end{array}$ & $\begin{array}{c}\text { Average } \\
\text { speer } \\
{[\mathrm{km} / \mathrm{h}]}\end{array}$ & $\begin{array}{c}\text { Driving } \\
\text { time } \\
{[\mathrm{s}]}\end{array}$ & $\begin{array}{c}\text { Average } \\
\text { speed } \\
{[\mathrm{km} / \mathrm{h}]}\end{array}$ \\
\hline $\mathrm{I}-\mathrm{II}$ & 18.9 & 18.0 & 1.6 & 42.5 & 1.6 & 42.5 & 1.4 & 48.6 & 1.2 & 54.0 \\
\hline II - III & 31.0 & 28.0 & 2.6 & 42.9 & 2.6 & 42.9 & 2.4 & 46.5 & 1.4 & 72.0 \\
\hline III - IV & 18.4 & 17.0 & 1.2 & 55.2 & 1.4 & 47.3 & 1.2 & 55.2 & 0.7 & 87.4 \\
\hline $\mathrm{IV}-\mathrm{V}$ & 9.8 & 9.2 & 0.8 & 44.1 & 1.0 & 35.3 & 0.8 & 44.1 & 0.4 & 82.8 \\
\hline $\mathrm{V}-\mathrm{VI}$ & 7.4 & \multirow[b]{2}{*}{8.5} & 0.6 & 44.4 & 1.0 & 26.6 & & & \multirow[b]{2}{*}{0.5} & \multirow[b]{2}{*}{61.2} \\
\hline $\begin{array}{c}\mathrm{VI}- \\
\text { collision }\end{array}$ & 6.8 & & & & 1.0 & 24.5 & & & & \\
\hline
\end{tabular}

Analysis of the course of the collision begins with the moment when the motorcycle appeared in the field of view of the camera (position 3A) (Fig. 2). The car 2 was then in the field of view of the camera near point II (position 2A), and the car 1 was in the field of view of the camera in the vicinity of point III (position 1A). The motorcycle 3 was situated next to the solid line, still on the right-hand lane (in accordance with the testimony of the motorcyclist), approximately $12.5 \mathrm{~m}$ behind the car 2 and about $42 \mathrm{~m}$ behind the car 1 . The car 2 was at this time about $25.5 \mathrm{~m}$ behind the car 1, which was situated at a distance of about $38 \mathrm{~m}$ from the right edge of the entry to the parking lot. Based on the analysis, it can be concluded that the average speed of the motorcycle $3 \mathrm{had}$ been reduced on the section between points IV and $V$ in the field of view of the video camera. The duration of passage between these points was equal to $0.4 \mathrm{~s}$ and was shorter than the statistical driver's average reaction time to an expected threat $\left(t_{\mathrm{r}}=1 \mathrm{~s}\right)$. At the moment when motorcycle 3 was in the field of view of the camera near point IV, the car 1 changed its direction and probably crossed the axis of the road (Fig. 3). The above findings show that the motorcyclist 3 , when deciding to start braking, reacted to a signal other than the car's changing direction. When considering the statistical average reaction time to an expected threat $\left(t_{\mathrm{r}}=1 \mathrm{~s}\right)$, it can be roughly determined where the motorcycle 3 was at the time when its rider could notice the threat. The motorcycle 3 was then outside the camera frame and was on the road in the spot obscured by point III (Fig. 4). This position was located approximately $40 \mathrm{~m}$ from the collision site and $25 \mathrm{~m}$ behind the rear bumper of the car 1 .

\section{Could the participants have noticed each other}

From the point of view of the driver of the car 1, it can be objectively assumed that he had the opportunity to observe the motorcycle 3 from the moment it pulled into the left lane from behind the preceding the car 2 . In that case, the motorcycle 3 would be visible in the side mirror of the car 1. In his testimony, the motorcyclist claimed to have changed the lane immediately after passing the solid axial line - that is before passing point II in the field of view of the camera. It can thus be argued that being in the 
field of view of the camera and after passing point II, the motorcycle was still behind the car 2 . Theoretically, with this position on the road $(3 \mathrm{~B}$, Figure 3 ) relative to the preceding vehicle, it could have still been moving in the right lane. Given the short distance (approx. $8 \mathrm{~m}$ ) between the vehicles in this phase of the accident, it was considered unlikely. It was more likely that the motorcycle had already been in the left lane. The motorcycle 3 was definitely in the left lane at the time shown in Figure 4 (position 3C), being located about 25 $\mathrm{m}$ behind the rear bumper of the car 1 , which at this time had already been significantly slowing down. The reduced speed of the car 1 could have been imperceptible to the motorcyclist due to the fact that his motorcycle was intensively accelerating in this phase of the collision. The driver of the car 1 would have had the objective chance to notice the motorcycle 3 in the side view mirror, had he observed the road behind him while decelerating. Assuming the correct arrangement of side mirrors in the car 1 , the motorcycle 3 , which was about 9 meters behind the rear bumper of the car 1 (position "D" in Figure 4), was then still outside the so-called driver's blind spot in the left side mirror. The motorcycle 3 performed the overtaking manoeuvre in a dynamic manner and in a short time greatly increased its speed. Such behaviour could have impeded the proper assessment of the traffic situation by the driver of the car 1 . In the present case, when the driver of the car 1 was making sure it was possible to turn left, the motorcycle 3 could have still been invisible behind the car 2 .

\section{Effect of speeding on the collision}

During its overtaking manoeuvre, the motorcycle 3 was moving at a speed greater than the speed limit in force in this area. Its calculated average speed between points III and IV in the field of view of the camera was $87.4 \mathrm{~km} / \mathrm{h}$; on that section of the road, the motorcyclist noticed the threat and decided to start braking. The motorcyclist could recognise the danger when was situated about 40 meters from the collision site (position 3C shown in Figure 4). About $2 \mathrm{~s}$ remained until the collision. With a distance of $40 \mathrm{~m}$ and under comparable conditions, the motorcycle could have stopped had its initial speed not been greater than $\mathrm{V}_{\max }=57.2 \mathrm{~km} / \mathrm{h}(15.9 \mathrm{~m} / \mathrm{s})$.

As the motorcycle was moving at a speed greater than the speed limit (on the section between points III and IV), the motorcyclist was unable to stop the motorcycle before the collision site. If the motorcycle had been moving there at the speed limit $(50 \mathrm{~km} / \mathrm{h})$, it would have travelled the distance $S_{h}$ in $t_{1 \mathrm{~m}}=40 / 13.8=2.9 \mathrm{~s}$. In order to leave the left lane with the entire length of the car, the driver of the car 1 needed a distance of about $18 \mathrm{~m}$. The determined average speed of the car 1 on the section from point $\mathrm{V}$ to the collision site was about $26 \mathrm{~km} / \mathrm{h}(7.2 \mathrm{~m} / \mathrm{s})$. The car 1 thus needed the time of $t_{10}=18 / 7.2=2.5 \mathrm{~s}$ to pull off the road before the oncoming motorcycle. It can be concluded that if the driver of car 1 had begun to turn left at the moment when the motorcycle was located about $40 \mathrm{~m}$ from the site of the collision and was moving at the speed limit, the car would have left the motorcycle's lane right before the motorcycle 3 .

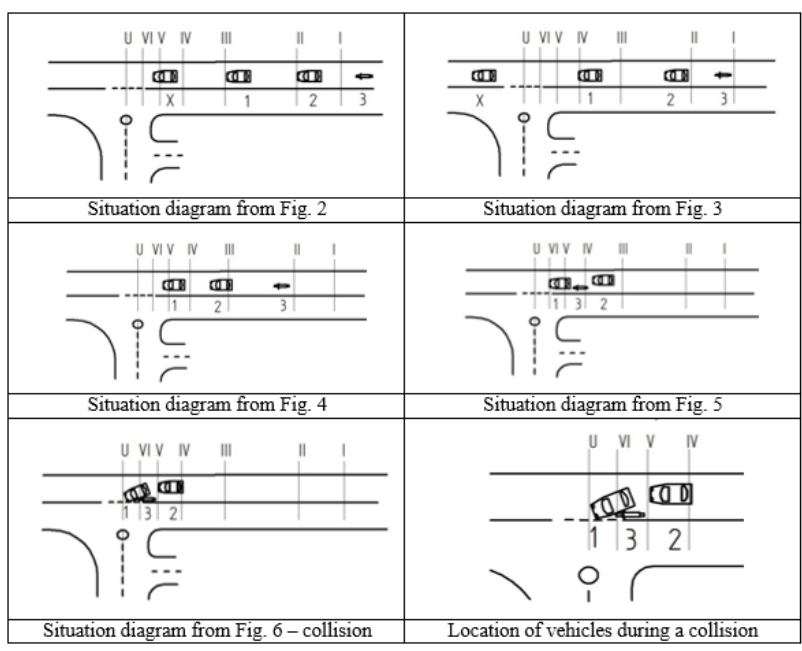

Fig. 7. Scheme of the accident: I, II, III, IV, V, VI - reference points, $\mathrm{U}$ - point of collision, $1,2,3, \mathrm{X}$ - vehicle identification.

\section{Conclusion}

In the presented accident, it is likely that the drivers were making the decisions to perform the manoeuvres at the time when they did not see each other. The course of the collision was registered by the monitoring system; however, this fact only seemingly facilitated the analysis of its cause. In the video recording, it can be observed that after the collision the car's left turn signal was on. However, it was not observed when it had been switched on. Detailed studies made it possible to reconstruct the motorcycle's speed profile in the individual phases of the pre-collision situation as well as to determine that it had exceeded the speed limit. It was also found that the signal which had spurred the motorcyclist to start a defensive manoeuvre was a signal other than the car's deviation from going straight. The authors' findings reconstructing the course of the collision may provide sufficient reason for the Court to find and state that the car's indicator was turned on appropriately early and that the testimony of the motorcyclist does not correspond to the factual evidence in this regard.

\section{References}

1. J. Caban, R. Karpiński, D. Barta, 11th International Scientific and Technical Conference on Automotive Safety, Casta Papiernicka, Slovakia, Apr. 18-20, 2018, XI International Science-Technical Conference Automotive Safety IEEE, Procedings Paper (2018)

2. R. Jurecki, M. Poliak, M. Jaskiewicz, Promet-traffic \& Transportation, 29, (2017)

3. L. Raslavicius, A. Kersys, S. Pukalskas, J. Bazaras, J. Jablonskyte, J. Ilgakojyte-Bazariene, R. Makaras, Public Transport, 7, 2, (2015)

4. R. Kampf, O. Stopka, I. Kubasakova, V. Zitricky, World Multidisciplinary Civil EngineeringArchitecture-Urban Planning Symposium (WMCAUS), Prague, Czech Republic, Jun. 13-17, 2016, Edited by: Drusa, M; Yilmaz, I; Marschalko, M; Coisson, E; Segalini, A., Procedia Engineering, 161, (2016) 
5. J. Lizbetin, O. Stopka, Open Engineering, 6, 1, (2016)

6. A. Kalasova, J. Mikulski, S. Kubikova, $16^{\text {th }}$ International Conference on Transport Systems Telematics (TST2016), Katowice Ustron, Poland, Mar. 16-19, 2016, Challenge of Transport Telematics, Edited by: Mikulski J., Communications in Computer and Information Science, 640, (2016)

7. L. Cernicky, A. Kalasova, Scientific Journal of Silesian University of Technology-Series Transport, 86, (2015)

8. T. Skrúcaný, J. Gnap, 6th International Scientific Conference on Dynamic of Civil Engineering and Transport Structures and Wind Engineering, Applied Mechanics and Materials, 617, (2014)

9. T. Skrucany, B. Šarkan, J. Gnap, Eksploatacja Niezawodność, Maintenance Reliability, 18, 1, (2016)
10. D. Clarke, P. Ward, C. Bartle, W. Truman, Accid. Anal. Prev., 39, (2007)

11. M. Elliott, C. Baughan, B. Sexton, Accid. Anal. Prev., 39, (2007)

12. M. de Lapparent, Accid. Anal. Prev., 38, (2006)

13. M. Horswill, S. Helman, Accid. Anal. Prev., 35 (2003)

14. W. Schneider, P. Savolainen, D. van Boxel, R. Beverley, Accid. Anal. Prev., 45, (2012).

15. C. Nicolas, T. Brenac, C. Perrin, J. Magnin, B. Canu, P. van Elslande, Accid. Anal. Prev., 49, (2012)

16. A. Shahar, E. van Loon, D. Clarke, D. Crundall, Accid. Anal. Prev., 44, (2012)

17. G.H. Walker, N.A. Stanton, P.N. Salmon, Accid. Anal. Prev., 43, (2011) 